\title{
Terrorismo y crisis mundial
}

- Ricardo Ribera

El presente texto se ha compuesto a partir de columnas de opinión publicadas por el autor en el periódico virtual El Faro (www.elfaro.net) sobre el tema.

El análisis de coyuntura, ése que se realiza al calor de los acontecimientos, a medida que éstos se producen, suele tener la caracteristica de una perspectiva cercana, vivida, a menudo emotiva, siempre arriesgada. Muy diferente a la frialdad y objetividad que caracteriza la labor del analista una vez el tiempo ha transcurrido y el proceso se ha desplegado, cuando dificilmente sorprenderá a quien lo escribe con eventos que desmientan sus valoraciones.

Pero, al filo de la coyuntura, el análisis tiene también sus propias ventajas. Se ve impregnado de autenticidad y espontaneidad, trasluce el gusto de la polémica, el tono del debate en curso al que se inserta el autor, los dilemas y alternativas posibles que están en el momento sobre el tapete de la discusión. De alguna manera, las columnas de opinión, de consumo generalmente efimero, forman parte de la propia historia que intentan narrar, discernir e influir.

Con los defectos y virtudes que le son propias al género, con sus errores y aciertos, ofrecemos agrupadas varias de estas columnas de opinión, análisis coyunturales que muestran en el nuevo contexto una perspectiva diferente a la que tuvieron en su momento. El lector sabrá valorar qué tanto de válido aún conservan y qué posible utilidad todavia ofrecen.

\section{Injusticia infinita}

No hay terrorismo bueno. Todo terrorismo es inhumano, horrendo, bestial, injustificable. Así de simple. Las terribles imágenes de las torres gemelas y del Pentágono, repetidas mil veces por el amarillismo televisivo, los relatos estremecedores de familiares y supervivientes, testigos y rescatistas, nos lo acaban de recordar, por si lo habíamos olvidado. Ha quedado de nuevo demostrado

Terrorismo y crisis mundial 
con el irrebatible argumento del sufrimiento humano. Han aflorado también, dentro y fuera de Estados Unidos, sentimientos hermosos de compasión y solidaridad que humanizan. También emergen poderosas las pasiones negativas: venganza, revanchismo, amenaza y bravuconería.

Se extiende el miedo ante la irracionalidad de los terroristas, que podrian tener planificados otros imprevisibles ataques. También un gran miedo ante la respuesta militar que pregona la hiperpotencia estadounidense. ¿Cuántas víctimas inocentes más se van a producir, a nombre ahora de la justicia? ¿Qué tanto más dolor humano habrá que causar para que se calme la sed de venganza y el público se sienta satisfecho?

Lo peor: de uno y otro bando, similar invocación a la bendición divina, a la guerra santa o a la "cruzada". Se sataniza al otro y se pretende santificar la carnicería. A ambos lados, víctimas y criminales. La gente sencilla, acá y allá, civiles y trabajadores empobrecidos la mayoría, poniendo los muertos para que quienes disputan el poder, los que proyectan las estrategias y calculan costos y beneficios, sigan su macabra partida de ajedrez. La guerra que hoy se anuncia huele a petróleo y a campos de amapola, a oleoductos y a heroína, a intereses económicos y a cálculos políticos, a posibles alianzas y a recomposición de los equilibrios de poder.

Todo terrorismo es malo. Pero hay uno peor. Es el terrorismo de Estado. Hay que corregir a los irreflexivos comentaristas de los canales televisivos: no es cierto que éste haya sido el mayor acto terrorista de la historia. Lanzar la bomba atómica sobre dos ciudades japonesas, por muy en guerra que se estuviera, fue puro terrorismo contra civiles inocentes y causó mil veces más destrucción y por lo menos cien veces más víctimas que el atentado contra el World Trade Center. El holocausto nazi contra los judios fue terrorismo extremo y sistemático como también sistemático y extremo ha sido el terrorismo de Israel contra los pobladores palestinos.

Y ¿qué decir del terrorismo de Trujillo, de Somoza, de Pinochet y de tantos otros dictadores sangrientos apoyados por Estados Unidos en América Latina, Asia y Africa? ¿Qué decir del terrorismo de Stalin, de Mao, de Ceaucescu, del Khmer rojo o de Sendero Luminoso? ¿Será que, cuando es de mi bando éste se vuelve bueno? ¿Podemos considerarnos civilizados y seguir razonando asi? ¿Puede construirse un mundo mejor, más justo y más humano haciendo politica de esta manera?

Pero los contras nicaragüenses y los talibán afganos fueron calificados en su momento de "luchadores por la libertad". Ahí está la biografia del propio Osama bin Laden -demonizado ahora sin pruebas como presunto autor intelectualquien fue por largo tiempo apoyado, armado, entrenado y financiado por Estados Unidos para enfrentar la intervención soviética en Afganistán. Ahí está la 
contrarrevolución cubana en su exilio dorado de la Florida, planeando impunemente atentados y campañas terroristas contra la isla.

¿De veras se trata de identificar y atacar a cualquier Estado que dé refugio y protección a grupos terroristas? Bien, pues se debería primero barrer en la propia casa. También en nuestro país. Antes de hacer el ridículo ofreciendo "ayuda militar" a la gran potencia del norte, que desde luego no la ha pedido, ni siquiera para tareas "humanitarias". Pero es el caso que hay dos compatriotas presos en Cuba convictos de colocar bombas en hoteles. Un señor cubano, Posada Carriles, sin turbante pero igual de peligroso, que incluso ha publicado un libro vanagloriándose del derribo de un avión de pasajeros y de incontables actos de terrorismo anticastrista, fue asesor del gobierno salvadoreño durante el pasado conflicto armado y después ha vivido por años tranquilamente en El Salvador, planeando y coordinando actos terroristas.

¿Estaremos por ello en la lista que ha elaborado Estados Unidos de los países sospechosos de colaboración con el terrorismo? Desde luego que no. Pero mientras no se muestren resultados de una investigación que en realidad nunca se inició, deberíamos de hecho estar en una tal lista. Ése es el punto. Lo mismo ocurre en el resto de la "civilización occidental": demasiados pecados para pretender lanzar la primera piedra y ni tan siquiera la segunda o la tercera.

La Organización de Naciones Unidas, la Corte Internacional de Justicia y el Tribunal Internacional para Crimenes contra la Humanidad son instancias sin duda limitadas. Seguramente sólo una justicia "finita" puedan ofrecer. Pero mucho más justa y conveniente que la actual campaña de la histeria y la venganza, a la que demasiado apresuradamente nuestro gobierno declara querer incorporarse.

Repitamos pues. No hay terrorismo bueno. Todo terrorismo es inhumano, horrendo, bestial, injustificable. Y debe ser rechazado. Así de simple.

\section{Teología versus tecnología}

La tecnología occidental arriesga enfrentarse con la teología que impregna al terrorismo islámico, como bien mencionaba en El Faro David Hernández en su, columna de la semana pasada. O como escribía en El Pais Carlos Alonso Zaldivar, diplomático español, "la indudable capacidad de occidente de matar pero sin disposición a morir, contra la postura que muestra el fundamentalismo islámico de morir matando". Ataques suicidas sólo realizables desde la desesperación.

Indudablemente hay acumulados sentimientos de odio y venganza que se ven reflejados en la inhumanidad increible de los atentados. Hay también sin duda valor y convicción demostrados en el carácter suicida de los ataques. No es elogio ni justificación. Es simplemente constatar que resulta irracional tildar de "cobarde" al atentado. No hay posibilidad de llevar a la justicia a los autores 
materiales. Éstos quedaron pulverizados. Se autoinmolaron. ¿Cómo ajusticiarlos?

Existe la insana costumbre de calificar de "fanáticos" a los del bando enemigo y de llamar "héroes" a los del propio bando. Así el análisis se vuelve imposible. Para analizar hay que intentar comprender. En este caso, entender lo que está sucediendo en ese mundo islámico del que probablemente proviene la agresión es condición para una respuesta adecuada, inteligente, capaz de generar un mundo más seguro. Contestar al odio con odio, con venganza la venganza y con terror a la agresión terrorista, no sólo etemizará la injusticia. También es la forma más segura de multiplicar la lista de voluntarios para próximos ataques suicidas. Sería caer en la trampa, hacer justo lo que está esperando quien calculó esta gigantesca provocación. Hacer del mundo un lugar todavía más inseguro y peligroso.

Estados Unidos ya perdió la primera de las batallas en esta guerra de símbolos: Tuvo que cambiar el nombre de la operación, puesto que justicia infinita tenía demasiadas connotaciones fundamentalistas. Se trata de no presentar la campaña como una reedición de las cruzadas. Al contrario, lo que interesa es atraer a los gobiernos musulmanes, a todos los que pueda, en esta gran coalición. La aparente estupidez de Berlusconi, el derechista presidente italiano, al insultar al Islam y atribuir a occidente el monopolio de la civilización, probablemente no sea tal. Hay esfuerzos deliberados de algunas fuerzas para utilizar la coyuntura a favor de su propio fundamentalismo politico. Lo mismo los ataques racistas y antimusulmanes que han empezado a producirse en suelo norteamericano por parte de indignados ciudadanos y supuestos patriotas. Contra los verdaderos intereses de su patria. Y del mundo.

No ayuda a reforzar la necesaria cordura y prudencia el conservadurismo duro y la patente mediocridad del mandatario estadounidense. "Se busca a Osama bin Laden vivo o muerto". El público norteamericano, los nostálgicos de la cultura del western, se entusiasman con la ocurrencia de Bush. No gusta en Europa. Sus aliados más estratégicos ven con preocupación este simplismo de la visión presidencial. Están solidarios. Pero es dificil que acompañen de forma activa a Estados Unidos en una aventura poco clara.

Afganistán fue el Vietnam de la Unión Soviética. Es otra cultura. También vive otro tiempo histórico. Ahí, en muchos aspectos se ha retornado a la Edad Media. Es lo que hace posible la temible combinación de lo atrasado con lo moderno. Secuestros aéreos realizados con navajas. Pero con gente preparada como pilotos. Impactar y destruir los símbolos de poder de la gran superpotencia con algo tan simple pero eficaz como un avión de pasajeros. Sabian lo que hacian. No así los bomberos y policías que ingresaban a las torres, ignorando que su colapso era seguro, ya calculado. Igualmente las imágenes en vivo y en directo. Tal vez también el monto de las pérdidas (entre 30 y 40 mil millones de 
dólares) y la más que probable recesión que se viene. ¿Una mente diabólica? No. Tan sólo una mente humana. Radicalizada, desesperada y medieval.

\section{Daños colaterales}

El eufemismo me pareceria delicioso, si no resultara tan macabro. Cada vez que alguna "bomba inteligente" comete la idiotez de caer donde no debe, o sea, sobre los civiles afganos, los militares estadounidenses aceptan que se han producido "daños colaterales". A veces la expresión viene acompañada por algún calificativo: "graves", "indeseados", "lamentables"...

Resultaría dificil deducir de qué se trata si no fuera por las imágenes de destrucción que en las noticias acompañan generalmente la referencia a tales "daños colaterales". Aqui sí se cumple el viejo dicho de que una imagen vale más que mil palabras. Hay un problema con el lenguaje militar, cínico y deshumanizado, que pretende encubrir el horror de la matanza con palabras técnicamente asépticas. Lo grave es que cuantas más víctimas inocentes produzcan Estados Unidos en Afganistán más paralelismos van a surgir entre el terrorismo suicida del que fueron víctimas y el terror sin bajas propias que su estrategia provoca. El autor intelectual de los atentados, feliz debe estar al ver lo fácilmente que su enemigo cayó en la trampa.

Son ya varias las "metidas de pata", perdón, los "daños colaterales" cometidos - sin duda involuntariamente - por las Fuerzas del Bien que han enviado Bush y Blair a derrotar a las Fuerzas del Mal. Primero fue una oficina de Naciones Unidas, días después las instalaciones de la Cruz Roja, algunas viviendas en Kabul y más tarde una aldea entera, una mezquita, un hospital y un asilo de ancianos. Y la cosa sigue. Sin que se le vea el final.

Pues, jmenos mal que las bombas son inteligentes! ¿Y los que las dejan caer, los que deciden y definen los blancos? ¿Serán igual de inteligentes? Porque por algún lado la cosa rebalsa estupidez. Un ejército que se toma la molestia de tirarles paquetes de comida a los civiles afganos para demostrarles que no es con ellos el pleito, pero que al mismo tiempo no es capaz de evitar los "daños colaterales" es harto dudoso que tenga éxito en darse a entender entre sus supuestos beneficiarios.

Si la estrategia es "ganar la mente y los corazones" (una fórmula ya conocida por el pueblo salvadoreño desde los sangrientos años de la contrainsurgencia) de los afganos, oprimidos bajo la férrea dictadura talibán, se impone otra pregunta: ¿son asimismo "inteligentes" los paquetes alimentarios que deja caer la Fuerza Aérea? Es decir, ¿cómo saben los Estados Unidos que esa comida no termina en manos de la milicia talibán? ¿No estará quizás el mismísimo Osama bin Laden saboreando las nutritivas raciones con que su enemigo pretende aislarlo de la población? 
Ya el Presidente Bush nos advirtió que ésta sería una guerra "diferente". Y de veras lo es: esta colaboración con la dieta alimenticia del enemigo es realmente novedosa e inesperada. Algo nunca visto en la historia universal de las guerras. ¿O acaso se trata sólo de una operación propagandística dirigida a nosotros, el público occidental? En tal caso seria indiferente quién consuma las raciones de comida en Afganistán, suponiendo que de veras alguien lo haga, visto que se les olvidó tomar en cuenta los hábitos alimentarios de esa cultura. La pensada seria que nosotros nos las traguemos. Es decir, que nos traguemos el cuento.

Naturalmente, es bien probable que quien esto escribe no haya comprendido en toda su sutileza la estrategia gringa y que esté totalmente equivocado en sus elucubraciones. Lo que ocurre es que conociendo por la historia que en su oportunidad Washington aplicó en América Latina una política que describía como "del palo y la zanahoria", pues uno se cree con derecho a desconfiar. Esto de bombardear alimentos y misiles suena sospechosamente similar.

El hecho es que antes de esta guerra ya habia unos tres millones y medio de refugiados afganos. La mayoría en lrán y Pakistán. ACNUR advierte que esa cifra se va a duplicar como consecuencia de las acciones militares de la alianza antiterrorista. $Y$ ningún pais vecino quiere más refugiados. Tras 22 años de guerra ininterrumpida, millones de minas enterradas, el tercer año seguido de sequía y ahora los bombardeos antiterroristas, el pueblo afgano debe estar al borde de la desesperación. Es decir, en el mejor caldo de cultivo para que nueva gente abrace el terrorismo como su última respuesta: la de morir matando. Cualquier persona sensata está de acuerdo: el terrorismo no debe quedar sin respuesta. Pero, ¿es una guerra la respuesta correcta?

\section{¿Libertad duradera?}

Ha cambiado el clima político en Estados Unidos a partir del 11 de septiembre. "Ya nada volverá a ser como antes", había exclamado el Presidente Bush pocas horas después de los atentados. ¿Simple información para la ciudadanía o advertencia? La frase sonaba amenazante. Tal vez lo era.

En Estados Unidos ya son varios los analistas políticos y comentaristas noticiosos que perdieron sus empleos por haber aventurado algún comentario crítico hacia la política oficial tras los acontecimientos del 11 de septiembre. Otros, con mayor fortuna, siguen trabajando, aunque recibieron y siguen recibiendo insultos y amenazas de muerte. Un trato parecido al que soportan los cerca de siete millones de la comunidad musulmana de Estados Unidos. Igual muchos otros inmigrantes de origen árabe, turco, paquistaní, hindú, afgano, iraquí, iraní...

El "sueño americano" puede fácilmente convertirse en una auténtica pesadilla para millones de inmigrantes o hijos de inmigrantes cuyo aspecto o color de 
la piel corresponda al cliché que de los terroristas se ha hecho el gran público. Se extiende en suelo norteamericano una creciente oleada de intolerancia y nuevos rebrotes de discriminación racial. Es grave. Ya se han dado las primeras víctimas mortales.

Es éste el otro terrorismo, xenófobo y de extrema derecha, que estaba presente desde antes en Estados Unidos. Se enmarca en la tradición del Ku-KlecxKlan. Su peligrosidad se había ya puesto de manifiesto a raiz de los hechos sangrientos de Waco, donde la secta de los davidianos se enfrentó militarmente a las autoridades, y más tarde con la bomba hecha explotar en un edificio federal de Oklahoma. Ahora todo apunta a que son grupos de extrema derecha los que están detrás de los atentados postales con esporas de ántrax. Es éste un terrorismo doméstico, made in USA, que pretende aprovechar la confusión y ansiedad creadas por el terrorismo foráneo. Y lo consigue.

Las libertades se contraen en la medida que la inseguridad cunde. Se perfila el retorno a un Estado policíaco, al estilo del marcatismo anticomunista y su tristemente famosa "cacería de brujas". Pocos días atrás, Emilio Lamo de Espinoza analizaba en el periódico español El Pais que Estados Unidos corre hoy "el riesgo de perder la libertad en la lucha por la libertad". Lo único duradero que resultaría de la actual campaña sería el autoritarismo.

La nueva ley antiterrorista que está impulsando Bush va en esa dirección. Si es sancionada permitirá a las autoridades estadounidenses capturar aquellos extranjeros de los que sospechen su participación o vínculos con el terrorismo. Y mantenerlos detenidos. Indefinidamente. Sin pruebas. Sin juicio. Sólo por sospechas. Ésa es al menos la intención del Ejecutivo, que probablemente se vea recortada por las dos cámaras legislativas. Habrá que ver qué tanto es suavizado por el Congreso y el Senado el actual proyecto de ley.

Principios elementales como la presunción de inocencia, el derecho de defensa, el derecho a un juicio justo, todo esto quedaría barrido por la nueva ley. Una especie de estado de excepción o estado de sitio permanente. No solamente se verian afectados los inmigrantes, sean indocumentados o residentes legales. También lo sería cualquier ciudadano norteamericano. La policía quedaría autorizada a intervenir teléfonos, correspondencia, correos electrónicos, páginas web, uso de tarjetas de crédito, cuentas bancarias. Podría utilizar sistemas de escucha en instalaciones hoteleras y residencias particulares. El derecho a la privacidad, del que tan celoso es el ciudadano en las democracias del primer mundo, se perdería irremisiblemente.

Gobiernos de países europeos donde es menor la paranoia por el terrorismo están impulsando, no obstante, leyes similares. La actual cruzada en defensa de la modernidad occidental, de los valores y principios democráticos, de las libertades civiles y los derechos individuales, del respeto a los derechos humanos, 
puede acarrear el paradójico efecto de dejar sin vigencia muchas de tales conquistas históricas. A nombre de la actual emergencia mundial por el embate del terrorismo. A nombre de hacer duradera la libertad.

\section{El derrumbe del neoliberalismo}

"La pregunta no es qué problema tenemos con el Estado; el Estado es el problema"-resumía pedagógicamente Ronald Reagan su convicción neoliberal. Esto quedó abandonado. Se da hoy un viraje hacia un pensamiento neoconservador, según el cual un Estado fuerte sea capaz de dar protección, así como de encabezar el esfuerzo por superar la recesión. Las prédicas de Hayek y sus discípulos de la Escuela de Chicago de repente quedaron out. ¿Quién se atreve ahora a recomendar Estado mínimo? ¿Quién a clamar porque el Estado "saque sus manos de la economía"?

$\mathrm{Al}$ contrario, vuelve ahora a leerse a Keynes en los principales círculos de poder norteamericanos. La experiencia histórica de las fórmulas para salir de la recesión, de los benéficos efectos de las guerras para la recuperación económica, de los contratos estatales millonarios y de las subvenciones como instrumento de política económica antirecesiva. Esto es lo que vuelve a estar de moda en el imperio.

No sólo en el mundo de las ideas. También en el mundo de las realidades. El contrato recién firmado con la empresa Lockheed para producir tres mil cazabombarderos de nuevo diseño se anuncia como el mayor de la historia. Asciende a la astronómica cifra de 225 mil millones de dólares. Por otro lado, tampoco ha renunciado la Administración Bush al programa militar de escudo antimisiles que propagandizó durante su pasada campaña electoral. El Estado sigue siendo el cliente único, o al menos el principal, para muchas grandes empresas. El consorcio militar-industrial puede respirar tranquilo: el fin de la guerra fria no significará el fin de sus negocios. Tampoco el de las contiendas bélicas. Más bien todo lo contrario.

El neoconservadurismo muestra parecida insensibilidad a la problemática social y humana que el neoliberalismo. Se aprovecha la coyuntura para dar luz verde a despidos en masa en sectores que estaban ya en crisis desde antes de los atentados. Al mismo tiempo, el Estado se prepara para dar cuantiosas subvenciones a los sectores económicos en problemas. También surgen voces denunciando la anterior irresponsabilidad, cuando se privatizaron esferas sensibles como la seguridad en los aeropuertos, la distribución de energía eléctrica, los servicios de agua potable...

Bajo el lema "la seguridad es la prioridad número uno" se percibe la corrección de todo eso y que viene un próximo proceso de desprivatización. Con todo ello, la ideología neoliberal se mira hecha escombros. Ya estaba agrietada y se 
ha terminado de derrumbar junto con las torres gemelas. Sólo falta que nuestros neoliberales de acá se enteren.

\section{Lo nuevo del terrorismo}

"El mundo ha cambiado - se nos repite- desde los atentados del $11 \mathrm{de}$ septiembre." Y realmente es la actual una situación diferente. Una diferencia que brota de la radical novedad del ataque terrorista. Los especialistas en el tema mencionan que en los últimos veinte años Estados Unidos, sus intereses o sus ciudadanos han sido objeto de no menos de 2 mil 400 atentados. Pero éste ha sido el primero de carácter global, que mató a ciudadanos de 60 países diferentes, planificado para ser transmitido en directo a nivel mundial. La magnitud del daño, el dolor, el caos y "el no saber qué hacer" que las autoridades reflejaron al inicio, frente a los ojos del mundo por el milagro de la tecnología actual de las comunicaciones, lo convirtieron enseguida en un golpe psicológico sin precedentes. Incredulidad y miedo, orgullo herido. La superpotencia humillada. Lágrimas de dolor y de rabia. Es nuevo.

Pero sobre todo es nuevo el hecho de que esta vez no hay mensaje. Nadie ha reivindicado el ataque. Nadie establece un por qué, un para qué o un quiénes. Anteriormente se habia dicho que en la posmodernidad "el medio es el mensaje"; en este caso, el mensaje es la propia acción terrorista. Es terrorismo posmoderno.

Tampoco hay mensajero. Es decir, desapareció, inmolado en su propia acción suicida. Como kamikaze. Pero un kamikaze del que no está clara su identidad, ni sus objetivos, ni las razones que lo animan. La única pista para deducir la procedencia del ataque es que el mensajero no trató de eludir su mortífero mensaje, lo asumió plenamente. Y tal como fue concebida era éste el único modo de cumplir su misión: sin intentar una vía de escape al destino fatal que él mismo se impuso. No hay ideología política capaz de llevar una convicción tan lejos. Tan sólo si combinada con el fanatismo religioso. Cruelmente, como en las guerras de religión de la Edad Media. Es terrorismo medieval.

De ahí lo grave de la equivocación estadounidense inicial, de presentar como "cruzada" la campaña antiterrorista, o como una "lucha entre el Bien y el Mal". A los que están dispuestos a morir invocando a Alá, poca mella iba a hacerles la satanización occidental. Al revés, conviene a sus fines poder presentar a la coalición mundial como el bloque de los infieles en lucha con los mil 200 millones que componen el mundo musulmán. No es ésta una guerra de religiones, pero podría llegar a serlo. El Islam actual es sumamente diverso y plural, pero van a potenciarse las corrientes antioccidentales si Occidente se equivoca en esta campaña. La falsa profecía del "choque de civilizaciones" sería entonces una de las que se vuelven verdaderas al generar su propio autocumplimiento. 
Surgiria una doble valoración ética: calificado de cobarde por Occidente, el ataque seria considerado heroico por una parte del mundo islámico. Osama bin Laden sabe lo que busca cuando afirma: "el mundo se ha dividido en dos; unos se alegraron y otros condenaron el atentado; unos están contra la campaña bélica en Afganistán y otros la apoyan". Éste es su razonamiento. La postura de Estados Unidos aparece sorprendentemente paralela. En palabras de su Presidente: "O están con nosotros, o están con el terrorismo." Es el mismo razonamiento de su adversario.

¿Será incoherente pronunciarse condenando el atentado y al mismo tiempo criticar la guerra contra Afganistán? ¿O la coherencia habrá que buscarla permaneciendo del lado de las víctimas? Pero víctimas las hay a ambos lados, en Nueva York y en Kandahar, en Washington y en Kabul.

\section{A tres meses del atentado}

La condena a los hechos del 11 de septiembre conlleva necesariamente, por idénticas razones éticas, la condena de la campaña antiterrorista. Lo contrario sería caer en la misma doble moral que inducía a Estados Unidos a llamar "luchadores por la libertad" a los que más tarde demonizaba. Así lo hizo Bush padre con Saddam Husein, ahora es el turno de Osama bin Laden y los talibán en tiempos de Bush hijo.

El terrorismo no estatal puede ser expresión de la desesperación, de la venganza y de la impotencia. Cuando no se es capaz por debilidad propia o por la fortaleza desmesurada del adversario de hacerle la guerra. Como sustituto. $O$ como recientemente alguien reflexionaba: "si se ha definido la guerra como la continuación de la política por otros medios, el terrorismo vendría a ser la continuación de la guerra por otros medios".

Inaceptable de todos modos. Pero también debería serlo la violencia de la guerra y solemos aceptarla. Como mal necesario. Incluso hay quien la ve como una forma de "destrucción creativa", que ayuda a superar crisis económicas. Conveniente a veces, sobre todo en tiempos de recesión.

En la nueva situación lo preocupante es que tiende a ir borrándose la delgada línea que teóricamente separa la guerra del terrorismo. La definición del terrorismo - ataque que busca generar víctimas civiles, con objetivos políticos, y que toma como blanco a la población - no resulta suficiente para una diferenciación definitiva. La guerra moderna suele usar métodos terroristas, sobre todo desde que se optó por la infraestructura económica como el blanco decisivo y se definió que quebrar la moral de combate del enemigo constituye el verdadero objetivo. Y porque los grupos terroristas emplean ahora refinadas tecnologias y armas de gran poder destructivo. 
Es lo que llevó a Bush a declarar formalmente los atentados como "un acto de guerra". Por su parte, los talibán han calificado los actos de guerra en su país de "actos terroristas". Nuevo paralelismo. Se difuminó la frontera teórica que separaba guerra y terrorismo. También la frontera práctica. Se está borrando en Afganistán.

Igual en territorio estadounidense. A la CIA le han regresado prerrogativas anteriores que legitiman los llamados "asesinatos selectivos". Sus agentes, otra vez gozarán de "licencia para matar". Justifica la mordaz critica de Máximo, famoso caricaturista del diario español El Pais: se buscan asesinos para matar criminales.

Mientras, los analistas discuten abiertamente en la prensa norteamericana la posible legitimidad de la tortura como método para prevenir atentados. Se argumenta la conveniencia de adoptar leyes como las de Israel, único Estado moderno donde ha sido legal el uso de la tortura, bajo el eufemismo de "aplicar presión fisica moderada" a los detenidos. De modo que con el lema "el país está en guerra" el poder aspira a tomar medidas, más propias de una dictadura militar, que de la democracia que pretende estar defendiendo.

No sólo el Estado. La sociedad norteamericana se mira dispuesta a aceptar cualquier restricción de los derechos y las libertades fundamentales, con tal de superar la inseguridad actual. Mantienen la zozobra nuevos atentados. Ahora son los envíos postales con ántrax. Nuevamente son mensajes de muerte los que llegan y de nuevo los mensajeros, esta vez los inocentes carteros, son los primeros en morir. Por si eso no fuera suficiente, renovados llamados de alerta de las autoridades mantienen el clima de temor ciudadano. "Se sabe de un próximo ataque terrorista", advierten. Pero no se sabe qué, ni se sabe dónde, ni se sabe cuándo. Y tampoco se sabe quién, ni por qué. ¿Para qué entonces los llamados de alerta? Tampoco eso se sabe.

No se sabe, pero se puede adivinar. Mientras se mantenga el miedo, resultará más fácil extender la militarización de la sociedad, los controles de todo tipo y escalar en el autoritarismo. Ahorrarse las protestas por los despidos masivos, muchos de los cuales ya estaban previstos desde antes del 11 de septiembre. Y presionar a los inmigrantes latinos, indeseados en tiempo de recesión. También acalla críticas a los programas de rearme del gobierno.

Los ideólogos neoconservadores del duro discurso anticomunista muestran su satisfacción. Bastará sustituir "comunismo" por la palabra "terrorismo" y el resto puede quedar como antes. Así ya no hará falta disfrazar de lucha contra el narcotráfico la injerencia en la guerra civil colombiana y podrá emprenderse la ofensiva contra las FARC y otras guerrillas marxistas a nombre de la cruzada contra el terrorismo. El Plan Colombia podría convertirse en la segunda fase de la campaña mundial antiterrorista. 


\section{Lo que hace falta}

No todos los cambios son para mal. Al fin, Estados Unidos se puso al día con sus pagos retrasados con la Organización de Naciones Unidas, cesando así esa política de chantaje. Levantó las sanciones contra India y Pakistán por sus ensayos nucleares y está haciendo por mejorar su relación con Irán. Y, lo más nuevo, está presionando a Israel para que deje de boicotear las negociaciones de paz, las lleve a feliz término y acepte un Estado palestino.

Falta mucho, no obstante, para poder considerar que la gran potencia ha corregido por fin el rumbo y utiliza su liderazgo para procurar hacer de éste un mundo más justo y más seguro. Debe corregir su política de inteligencia, para que la CIA deje de reclutar y entrenar cuervos, que más adelante le sacarán los ojos, a su amo o a cualquier vecino. Debe cesar el uso abusivo y terrorista de su fuerza militar, para poder derrotar ideológicamente y aislar el terrorismo hoy existente en el mundo.

Debe aplicarse su propia receta y dejar de tolerar, albergar y ayudar a grupos terroristas en su propio territorio. El exilio dorado de la contrarrevolución cubana en la Florida debe terminar. Organizaciones como la Fundación Nacional Cubano Americana, FNCA, señalada de haber financiado las actividades de gentes como Luis Posada Carriles, confeso terrorista hoy preso en Panamá, deben ser ilegalizadas e investigadas por la justicia.

Falta que apoye la creación y ratifique la puesta en marcha del Tribunal Penal Internacional, del que ha sido uno de los únicos siete Estados en oponerse, para que los genocidas y los criminales de guerra enfrenten la justicia y nos ahorremos campañas militares de represalia y venganza como la actual.

Debe haber control de los paraísos fiscales y de las cuentas secretas, a lo que Estados Unidos se ha opuesto hasta ahora pero que resulta crucial para contrarrestar, tanto el terrorismo como el crimen organizado y la corrupción de muchos políticos. Deben avanzarse los programas para la eliminación de las armas de destrucción masiva, las químicas y biológicas, así como las nucleares. Y dar a la ONU el poder que hasta ahora se le ha negado y poner fin al privilegio del veto de que gozan cinco naciones, para que pueda cumplir su misión de procurar la paz, el progreso y la equidad en el mundo.

Sin un dramático cambio de orientación de la nación más poderosa del mundo, dificilmente la campaña actual conseguirá poner un punto final al terrorismo y la camiceria seguirá. Estados Unidos ha pedido al mundo solidaridad. Está en su derecho y la merece. Por ahora, la crítica se constituye en una forma de solidaridad, tal vez la mejor. Porque señala un camino y una base de principios. Sin ellos, los medios que se utilizan pueden terminar atropellando los nobles fines que se proclaman. Sin ellos, la civilización se arriesga a degenerar en una barbarie parecida a la que se enfrenta. Sin ellos, pierde todo sentido la actual campaña por hacer duradera la libertad y posible la justicia. 